\title{
Factors Contributing to Patient Default of Tuberculosis Treatment in Health Facilities Within Nakuru East and West Sub-Counties-Kenya
}

\author{
Ronald Omenge Obwoge ${ }^{1, *}$, Emily Sigilai ${ }^{2}$, Richard K. A. Sang ${ }^{1}$ \\ ${ }^{1}$ Department of Community Health, Faculty of Health Sciences, Egerton University, Nakuru, Kenya \\ ${ }^{2}$ Department of Tuberculosis and Leprosy, Ministry Health, Nakkuru County, Kenya \\ Email address: \\ obwogeo@yahoo.com (R. O. Obwoge) \\ *Corresponding author
}

\section{To cite this article:}

Ronald Omenge Obwoge, Emily Sigilai, Richard K. A. Sang. Factors Contributing to Patient Default of Tuberculosis Treatment in Health Facilities Within Nakuru East and West Sub-Counties-Kenya. Journal of Family Medicine and Health Care.

Vol. 2, No. 4, 2016, pp. 108-113. doi: 10.11648/j.jfmhc.20160204.23

Received: September 9, 2016; Accepted: November 12, 2016; Published: December 12, 2016

\begin{abstract}
Tuberculosis is an infectious disease caused by mycobacterium tuberculosis (MTB) which is transmitted through the air or by ingesting infected milk or meat (bovine $\mathrm{Tb}$ ). It is major public health problem worldwide. The study sought to determine factors contributing to patient defaulting to tuberculosis treatment in Nakuru East and West Sub-Counties, Nakuru County. The study adopted a descriptive cross-sectional study design. The target populations were patients who had defaulted TB treatment in various health facilities of Nakuru East and West Sub-Counties, Nakuru County. They were estimated to be 70 clients according to District Health Information System, 2015. The study utilized convenient sampling method to access the respondents among the traced TB defaulters. Interview schedule was used as data collection tool. Data collected was analyzed by use of Statistical Package for Social Sciences (SPSS) version 21 and presented by use of tables. The study result found that majority of the respondents was male $38(90.5 \%)$ while the minority was female $4(4 \%)$. Counseling services to were; 7 (16.7\%) only counseled during the first visit for treatment, $17(40.5 \%)$ on each visit, $13(31 \%)$ once a while $5(11.9 \%)$ were never counseled $26(61.9 \%)$ of the respondents were casual laborers, $3(7.1 \%)$ were self-employed, $3(7.1 \%)$ were employed and $7(16.7 \%)$ were dependants and that $2(9.5 \%)$ of the respondents believed that TB can be cured using traditional medicine while $40(90.5 \%)$ did not belief that. The study recommends that health education should be intensified within the communities, focusing on all the TB patients to be intensified, particularly at the beginning of treatment, with reinforcement at each visit using the local language. This intensification should be comprehensive to include duration of treatment, possible side effects and how to deal with them, consequences of not completing TB treatment and the dangers of using traditional medicines during TB treatment.
\end{abstract}

Keywords: Tuberculosis Treatment, Defaulting, Compliance, Contributing Factors

\section{Introduction}

\subsection{Background Information}

Tuberculosis is an infectious disease caused by mycobacterium tuberculosis (MTB) which is transmitted through the air or by ingesting infected milk or meat (bovine $\mathrm{Tb}$ ) and it is both preventable and curable (WHO, 2006; Caminero 2003;24). People who have pulmonary tuberculosis (TB disease in the lungs) can infect others through droplets infection when they cough, sneeze or talk
(WHO 2006). The prevalence of tuberculosis among close contact of infectious patients can be about 2.5 times higher than in the general population (Lenons, Mator, Pedral, Sampaio and Netto, 2004).

Tuberculosis (TB) has been declared a global public health problem by World Health Organization (WHO) (WHO, 2012). The disease causes significant mortality and morbidity globally and with the advent of the human immune deficiency virus (HIV) epidemicTB is regarded as a worldwide public health challenge (Kochi, 1991; WHO, 1992). The rising incidence of TB due to the effect of HIV in 
both developed and developing countries is well recognized (Narain et al, 2010).

Besides well-known risk factors, the most important unresolved challenge in TB control is the treatment completion. Treatment will only be effective if the patient completes the regimen which includes a combination of drugs recommended by the physician. Poor compliance contributes to the worsening of the TB situation by increasing incidence and initiating drug resistance. Resistance to anti-TB drugs has also emerged as an important obstacle in the control of Tuberculosis disease. Worldwide patient compliance with anti-TB therapy, with an estimate of as low as $40 \%$ in developing countries, remains the principle cause of treatment failure (Fox, 2013).

The World Health Organization recommends at least 90\% cure rate of all diagnosed TB cases (WHO, 2014). In order to achieve this cure rate, compliance needs to be in the order of $85-90 \%$ (Murray et al, 2010). It is therefore beneficial to study factors related to poor compliance, default and abandonment of treatment, which include socio-cultural, service related factors and treatment related factors (cantwellet al, 2014).

\subsection{Problem Statement}

Tuberculosis (TB) is major public health problem worldwide. The number of cases for TB is increasing by $2.4 \%$ per year with nearly 8.9 million new cases in 2004. In Nepal it is estimated that $45 \%$ of the total population is infected with TB. 44,000 people develop active TB and 8-11,000 people die each year from this disease.

In Africa TB remains a major health problem in many tropical countries, including Ghana. Kwaebibirim is one of 19 districts in the Eastern region of Ghana. It is a rural district with a poorly developed infrastructure. Unemployment levels are high, thus contributing to a high poverty level. The resource capacity of the district is low with poorly motivated and ill-equipped staff. All these factors are grouped into socio-cultural, service related and treatment related factors contributing to spread of TB. Diagnostic and treatment procedures are ill defined (GHS/KDHMT, 2007:15). Most TB cases can be cured with current anti-TB drugs. To be effective, however, the drugs must be taken exactly as prescribed (WHO 2000:3). The MDR TB rate in Ghana was 1.9\% (USAID 2008).

In Kenya, according to McLean (2014), the factors contributing to non-adherence can be grouped into three categories, namely: patient-related, healthcare and treatment factors. The government of Kenya policy provides for free TB treatment. This includes consultation at clinics, laboratory services and non-payment for drugs. Despite the availability of free TB treatment the default rate of the DOTS program in Kenya was $35 \%$ (McLean, 2014). According to the Kenya National Tuberculosis Program (NTP), the national default rate should not exceed 3\% (WHO 2014). High default rates lead to large numbers of patients suffering from MDR TB. In 2007, the MDR TB rate in Ghana was 1.9\% (USAID, 2008).
In Nakuru Level 5 Hospital, some clients who were noncompliant to treatment later developed Multi-drug resistant TB (MDR-TB) and are currently on second line treatment. This poses a threat not only to themselves but to the community as a whole. While studies on the factors associated with poor compliance have been carried out globally and in Sub-Saharan Africa, there are no published studies for Nakuru County as a whole. Therefore, without knowledge on factors associated with poor compliance to TB treatment in these sub-counties, it will be difficult to address the situation.

This study's findings form a basis by which the health care workers in Nakuru East and West Sub-Counties uses to employintervention measures that would increase the compliance of tuberculosis treatment among the TB patients in the sub-counties.

\subsection{Objectives of the Study}

\section{Broad Objectives}

To determine factors contributing to defaulting to TB treatment in Nakuru East and West Sub-Counties, Nakuru County, Kenya.

\section{Methodology}

\subsection{Study Area}

This study was conducted in Nakuru East and West SubCounties in Nakuru County, Kenya. Nakuru town is located North-west of Nairobi and the fourth largest urban centre in Kenya. It is situated at an altitude of Latitude: $0^{\circ} 16^{\prime} 59^{\prime \prime} \mathrm{S}$ Longitude: $36^{\circ} 04^{\prime} 00^{\prime \prime} \mathrm{E}$ and Elevation above sea level: $1848 \mathrm{~m}$ $=6062 \mathrm{ft}$. Nakuru has an area of $290 \mathrm{~km}^{2}$ of which $44 \mathrm{~km}^{2}$ are covered by the lake Nakuru. It is $139 \mathrm{~km}$ from Nairobi and $579 \mathrm{~km}$ from Mombasa. Nakuru County is populated by people from the whole of Kenya and even outside the country. The total population of Nakuru East and West sub counties is approximately 390,998 (DHIS 2015). Most activities in the town is business within the $\mathrm{CBD}$, some are employed in agriculture sector, manufacturing and tourism which are the economy of Nakuru. The crops mainly grown are coffee, wheat, barley and beans. The industries include flour milling and grain ginneries. The tourist attractions sites include Lake Nakuru where there are flamingoes, lake Nakuru National Park, Menengai crater and Hyrax Hills prehistoric site.

\subsection{Study Population}

All TB patients registered within health facilities in Nakuru East and West sub counties. The study target population was those patients not complying with TB treatment in Nakuru East and West Sub-Counties who were 70 in number (DHIS, 2015).

\subsection{Study Sample and Sampling Techniques}

The study adopted a census survey to interview all the $\mathrm{Tb}$ defaulters who were 70 in number. They were traced TB 
defaulters in Nakuru East and West Sub-Counties.

\subsection{Study Design and Selection Criteria}

The researcher used census survey based available clinic records. Included only traced Adults TB defaulters in Nakuru East and West Sub-Counties and willing to participate in the study. And excluded:

- Those defaulters who were not found and brought back to treatment during study.

- Mentally ill clients.

- transfer in and out

\subsection{Study Variable}

a Independent Variables

TB treatment defaulters

b Dependent Variables

- Socio-cultural factors leading to TB treatment default.

- Economic factors leading to TB treatment default.

- Service related factors leading to TB treatment default.

- Treatment related issues contributing to TB treatment default.

\subsection{Data Collection Tool}

The main data collection tool used in this study was a questionnaire.

\subsection{Data Analysis and Presentation}

The data collected was analyzed by use of Statistical Package for Social Sciences (SPSS) version 21.

\subsection{Ethical Considerations}

Ethical approval done from Egerton University, Ethics and Research Committee and Permission was sought from Director of Health Nakuru County. Informed consent from each of the respondent was sought and Confidentiality of information and anonymity of the respondent was upheld.

\section{Result}

\subsection{Demographic Characteristics of Respondents}

Study's response rate was $60 \%, 70$ questionnaires were distributed to the respondents only 42 of them were returned.

Table 1. Response rate.

\begin{tabular}{lll}
\hline Response & Frequency & Percentage \\
\hline Expected response & 70 & 100 \\
Received response & 42 & 60 \\
Non response & 28 & 40 \\
\hline
\end{tabular}

Majority of the respondents were male 38 (90.5\%) and female $4(4 \%)$. Among the respondents $2(4.8 \%)$ were below 20 years of age, 19 (45.2\%) were between 21-30 years old, $10(23.5 \%)$ were between $31-40$ years old and $11(26.2 \%)$ were between 41-50 years old, none of them were above 50 years. Mean age? All the respondents (42 100\%) were Christians. Marital status 7 (16.7\%) single, 14 (33.3\%) married, 18 (42.9\%) divorced/separated and 3 (7.1\%) widowed.

\subsection{Health Care Related Factors Leading to Defaulting TB Treatment}

a Awareness of TB disease

Study result suggests that $100 \%$ the respondents were aware of TB disease.

b Turning back patients by health care providers when seeking TB treatment services

Table 2. Turning back patients by health care providers when seeking TB.

\begin{tabular}{lll}
\hline Frequency & Frequency & Percent \\
\hline Yes & 37 & 88.1 \\
No & 5 & 11.9 \\
Total & 42 & 100.0 \\
\hline
\end{tabular}

The study result in table 2 indicate that $37(88.1 \%)$ were not turned back by health care providers when they went for TB treatment while $5(11.9 \%)$ claimed to be turned back.

c Frequency of counseling on TB treatment

Table 3. Frequency of counseling on TB treatment.

\begin{tabular}{lll}
\hline Frequency & Frequency & Percent \\
\hline On the first visit & 7 & 16.7 \\
On each visit & 17 & 40.5 \\
Once a while & 13 & 31.0 \\
Never counseled & 5 & 11.9 \\
Total & 42 & 100.0 \\
\hline
\end{tabular}

The result in table 3 indicate that 7 (16.7\%) of the respondents were only counseled during the first visit for treatment, 17 (40.5\%) were counseled on each visit, $13(31 \%)$ were counseled once a while $5(11.9 \%)$ were never counseled.

d Health care workers attitude in facilities

The study sought to determine attitude of health care workers at facilities to clients. Result presented in table 4.

Table 4. Health care workers attitude in facilities.

\begin{tabular}{lll}
\hline Frequency & Frequency & Percent \\
\hline Friendly & 12 & 28.6 \\
Empathetic & 7 & 16.7 \\
Rude & 14 & 33.3 \\
Uncaring & 9 & 21.4 \\
Total & 42 & 100.0 \\
\hline
\end{tabular}

Study result in table 4 indicate that $(1228.6 \%)$ of the respondents viewed health care workers as friendly during treatment, (7 16.7\%) as empathetic, (14 33.3\%) as rude and (9 21.4\%) as uncaring. Also $100 \%$ agreed that drugs were always available on their scheduled visits.

e Time spend in clinic/facility for monthly refill of TB treatment

The study sought to determine economic status of respondents. Result presented in table 5. 
Table 5. Time spend in clinic/facility for monthly refill of TB treatment.

\begin{tabular}{lll}
\hline Frequency & Frequency & Percent \\
\hline Less than 1 hour & 7 & 16.7 \\
$2-3$ hours & 17 & 40.5 \\
3 hours & 13 & 31.0 \\
Total & 42 & 100.0 \\
\hline
\end{tabular}

The result in table 5 indicate that $7(16.7 \%)$ of the respondents spend less than 1 hour for monthly refill of TB treatment, 17 (40.5\%) spend 2-3 hours and 13 (31.0\%) spend 3 hours and above;

f Association of time spend at the clinic with defaulting of drugs

The study sought to analyze the association between times spent at the clinic with defaulting. Result presented at table 6 .

Table 6. Association of time spend with defaulting of drugs.

\begin{tabular}{lll}
\hline Frequency & Frequency & Percent \\
\hline Yes & 4 & 9.5 \\
No & 38 & 90.5 \\
Total & 42 & 100.0 \\
\hline
\end{tabular}

The result in table 6 indicates that $4(9.5 \%)$ of the respondents indicated that time spend in the facility for monthly refill of TB treatment contributed to their default while $38(90.5 \%)$ said that it did not contribute.

g Privacy during clinic visits

The study sought to determine clinic privacy and defaulting. The result in table 7 .

Table 7. Privacy during clinic visits.

\begin{tabular}{lll}
\hline Frequency & Frequency & Percent \\
\hline Yes & 5 & 11.9 \\
No & 37 & 88.1 \\
Total & 42 & 100.0 \\
\hline
\end{tabular}

The result in table 7 indicate that Majority of the respondents $38(88.1 \%)$ indicated no privacy during clinic visits while the minority $5(11.9 \%)$ agreed there was privacy.

$\mathrm{h}$ Distance travelled to collect $\mathrm{Tb}$ medicine

Table 8. Distance travelled to collect Tb medicine.

\begin{tabular}{lll}
\hline Frequency & Frequency & Percent \\
\hline Less than $5 \mathrm{~km}$ & 3 & 7.1 \\
$5-10 \mathrm{~km}$ & 12 & 28.6 \\
$11-15 \mathrm{~km}$ & 16 & 38.1 \\
Over $15 \mathrm{~km}$ & 11 & 26.2 \\
Total & 42 & 100.0 \\
\hline
\end{tabular}

The result in table 8 indicate that $3(7.1 \%)$ of the respondents had travelled for less than $5 \mathrm{~km}$ to collect TB medicine, $12(28.6 \%)$ of the respondents travelled $5-10 \mathrm{~km}$ to collect TB medicine, $16(38.1 \%)$ travelled $11-15 \mathrm{~km}$ while 11 $(26.2 \%)$ travelled over $25 \mathrm{~km}$.

i Association of distance of travel with treatment default
Table 9. Association of distance of travel with treatment default.

\begin{tabular}{lll}
\hline Response & Frequency & Percent \\
\hline Yes & 11 & 26.1 \\
No & 31 & 73.8 \\
Total & 42 & 100.0 \\
\hline
\end{tabular}

Table 9 indicate $11(26.1 \%)$ of the respondents associated distance of travel with their default of treatment while 31 (73.8\%) did not associate.

\subsection{Socio-Economic Factors}

a Respondents occupation

Table 10. Occupation.

\begin{tabular}{lll}
\hline Source of income & Frequency & Percent \\
\hline Casual laborer & 26 & 61.9 \\
Self employed & 3 & 7.1 \\
Employed & 3 & 7.1 \\
Dependant & 7 & 16.7 \\
Total & 42 & 100.0 \\
\hline
\end{tabular}

Table 10 indicates that $26(61.9 \%)$ of the respondents were casual laborers, 3 (7.1\%) were self-employed, 3 (7.1\%) were employed and 7 (16.7\%) were dependants.

b Availability of food while taking TB drugs

Table 11. Availability of food while taking TB drugs.

\begin{tabular}{lll}
\hline Availability of food & Frequency & Percent \\
\hline Always available & 32 & 76.2 \\
Not Always available & 10 & 28.8 \\
Total & 42 & 100.0 \\
\hline
\end{tabular}

The result in table 11 indicates that $32(76.2 \%)$ of the respondents said that food was always available when they were taking TB drugs while 10 (28.8\%) said that food was not always available while they were taking $\mathrm{Tb}$ drugs.

c Nutritional supplements from health facilities

Table 12. Nutritional supplements from health facilities.

\begin{tabular}{lll}
\hline Response & Frequency & Percent \\
\hline Yes & 4 & 9.5 \\
No & 38 & 10.5 \\
Total & 42 & 100.0 \\
\hline
\end{tabular}

The results in table 12 revealed that $4(9.5 \%)$ of the respondents said that they receive nutritional supplements from health facilities while $38(90.5 \%)$ did not receive nutritional supplements.

d Use of drugs or other substances

Table 13. Use of drugs or other substances.

\begin{tabular}{lll}
\hline Drugs or substances taken & Frequency & Percent \\
\hline Alcohol & 14 & 33.3 \\
Tobacco & 4 & 9.5 \\
Cigarettes & 10 & 28.6 \\
None & 14 & 33.3 \\
Total & 42 & 100.0 \\
\hline
\end{tabular}

The results in table 13 indicate that $14(33.3 \%)$ of the respondents used alcohol, 4 (9.5\%) used tobacco, 10 (28.6\%) 
used cigarette and 14 (33.3\%) did not use alcohol or any other substances.

e Cost of transport to get to health facility

Table 14. Cost of transport to get to health facility.

\begin{tabular}{|c|c|c|}
\hline Cost & Frequency & Percent \\
\hline Less than Kshs 100 & 14 & 33.3 \\
\hline Kshs 100 -Kshs 500 & 4 & 9.5 \\
\hline Total & 42 & 100.0 \\
\hline
\end{tabular}

The result in table 14 indicate that that $35(83.3 \%)$ of the respondents spent less than Kshs 100 to get to the health facility for TB treatment, 7 (16.7\%) spent between Kshs 100Kshs 500 while none of them spent over Kshs 500.

\subsection{Cultural Factors}

a Curing of TB using Traditional medicines

Table 15. Curing of TB using Traditional medicines.

\begin{tabular}{lll}
\hline Response & Frequency & Percent \\
\hline Yes & 2 & 9.5 \\
No & 40 & 90.5 \\
Total & 42 & 100.0 \\
\hline
\end{tabular}

The result in table 15 indicates that $2(9.5 \%)$ of the respondents believed that $\mathrm{TB}$ can be cured using traditional medicine while $40(90.5 \%)$ did not belief that.

b Cultural beliefs in the community associated with TB

Table 16. Cultural beliefs in the community associated with TB.

\begin{tabular}{lll}
\hline \multicolumn{1}{c}{ Response } & Frequency & Percent \\
\hline Yes & 8 & 14.3 \\
No & 36 & 85.7 \\
Total & 42 & 100.0 \\
\hline
\end{tabular}

The result in table 16 indicate that majority of the respondents $36(85.7 \%)$ said that their communities did not have cultural beliefs associated with TB treatment while 8 $(14.3 \%)$ said there were cultural beliefs in their community associated with TB drugs.

\subsection{Treatment Related Factors}

Reasons for not giving TB treatment

The following were some of the reasons given for defaulting TB drugs:

Table 17. Cultural beliefs in the community associated with TB.

\begin{tabular}{lll}
\hline Reasons & Frequency & Percent \\
\hline Treatment takes very long to complete & 10 & 23.8 \\
Side effects of anti TB drugs & 13 & 30.95 \\
Too many pills to take daily & 12 & 28.57 \\
Travelled to native home & 4 & 9.5 \\
Assumed treatment is complete & 3 & 7.1 \\
Total & 42 & 100.0 \\
\hline
\end{tabular}

\section{Discussion}

\subsection{Health Care Related Factors}

The study suggest that $12(28.6 \%)$ of the respondents were of the view that health care workers were friendly during treatment, $7(16.7 \%)$ viewedhealth workers as empathetic, while $14(33.3 \%)$ viewed healthcare workers as rude and 9 $(21.4 \%)$ viewedthem as uncaring. These findings are in agreement with Mokgoadi (2002) study which suggests that a preventative measure to decrease non-compliance to $\mathrm{TB}$ treatment is to improve the attitude of health-care workers dealing with TB patients.

The study found that $3(7.1 \%)$ of the respondents had travelled for less than $5 \mathrm{~km}$ to collect TB medicine, 12 $(28.6 \%)$ of the respondents travelled $5-10 \mathrm{~km}$ to collect TB medicine, $16(38.1 \%)$ travelled $11-15 \mathrm{~km}$ while $11(26.2 \%)$ travelled over $25 \mathrm{~km}$. This is in agreement with Kaonaet at. (2004) study that reflects poor access to a health care facility as an effect on compliance to TB treatment as healthcare services may be inaccessible to patients.

\subsection{Socio-economic Factors}

Study indicates that $26(61.9 \%)$ of the respondents were casual laborers, 3 (7.1\%) were self-employed, 3 (7.1\%) were employed and $7(16.7 \%)$ were dependants. This being an indication that defaulting is associated with low socioeconomic status. This being in agreement to Malik \& Ahmad (2009: 17) study that indicates $67 \%$ of non-compliant TB patients were of lower social class, $28 \%$ from the middle and $5 \%$ from higher classes.

\subsection{Cultural Factors}

The study found that $2(9.5 \%)$ of the respondents believed that TB can be cured using traditional medicine while 40 $(90.5 \%)$ did not belief that. These findings contradict Kobe (2006) who states that that non-compliance of most TB patients with prescribed treatment is caused, to a large extent, by cultural beliefs.

\subsection{Treatment Related Factors}

The study revealed some following reasons given for defaulting TB drugs: 10 (23.8\%) of the respondents indicated that they defaulted treatment because it takes very long to complete, $13(31.1 \%)$ because of side effects of the drugs, 12 $(28.6 \%)$ due to pill burden per day, $4(9.5 \%)$ travelled to their native homes and $3(7.1 \%)$ they assumed treatment is complete. This concur with Mokgoadi (2002) study which found that TB treatment is still perceived by the majority of patients as long, agonizing and cumbersome, and there are still some doubts as to whether the disease is curable.

\section{Conclusion}

Defaulting is associated with income levels. The majority of healthcare providers are not friendly to their TB patients; most patients spend 2-3 hours to get refill of TB treatment 
and majority of the respondents $5-15 \mathrm{~km}$ to access TB treatment. More males than females default TB treatment. Also patients of reproductive age between 21-40 years are the main TB treatment defaulters in Nakuru East and West sub-counties. It was also concluded that divorced /separated and married patients are also major defaulters and that patients with low education level default more on TB drugs. Most patients are aware of TB treatments, patients are counseled on each visit on TB medication, Tb drugs have been made available in health facilities, majority of healthcare providers are not friendly to their TB patients, most patients spend 2-3 hours to get refill of TB treatment and majority of the respondents $5-15 \mathrm{~km}$ to access $\mathrm{TB}$ treatment.

\section{References}

[1] Bernard, N, Margaret, N, Peter, K, Emphantus. W, Vicort, V, D And Francis O (2011). Factors associated with default form treatment among tuberculosis patients in Nairobi province Kenya; a care control study. Nairobi Kenya university f Nairobi.

[2] Beuchamp, T. L. and Childress, J. F. (2009). Principles of biomedical ethics. 6th edition. New York: Oxford university press.

[3] Caminero. JA (2008). Likelihood of generating MDR- TB and XDR- Tb under adequate national tuberculosis control programme implementation. International journal for TB and lung diseases 12 (8); 869-877.

[4] Carpara, J. (2009). Convenience sampling applied to research. New York: Oxford.

[5] Comb S. K. (2010). The practice of nursing research: conduct, critique and utilization. 5th edition. St Louis: Saunders Elsevier.

[6] Connolly. C, Davies, G. R. \& Wilkinson, D. (2009). Who fails to complete tuberculosis treatment. International Journal against Tuberculosis and Lung Disease, 3 (12): 1 081-7.
[7] Eastwood, S. V. \& Hill, P. C. (2008). A gender-focused qualitative study of barriers to accessing tuberculosis treatment in the Gambia, West Africa. International Journal for Tuberculosis and Lung Diseases, 8 (1): 70-75.

[8] Gad, A, Ahmed, M. A, Aida, A. A, Zahira, M. \& Sunny, S. (2010). Compliance with anti-tuberculosis drugs among tuberculosis patients in Alexandria, Egypt PLosMed, 3 (2): 244-250.

[9] Gandhi, R. (2010). Treatment compliance and its contributory factors on pulmonary TB. Unpublished Masters dissertation. Bangalore: University of Health Sciences.

[10] Glatthaar, E. (2013). Tuberculosis Control in South Africa. The South African Medical Journal, 17: 36-41.

[11] Gnennassi A (2007). Factors that contribute to noncompliance with TB treatment in regional TB centre; Burkina Faso medical journal.

[12] Hodgson, I. J, Desclaux, A. \& Mukasa, D. S. (2009). Barriers to better care for people with AIDS in developing countries, British Medical Journal, 329: 1281-1283.

[13] International Union against TB and Lung Disease (IUATLD). (2010). Management of TB: A guide to the essentials of good practice. $6^{\text {th }}$ edition. Paris: Misereor.

[14] ITECH (2008). Physician training on the use of the national guidelines for the management of $\mathrm{Tb}$.

[15] Jonakan, N. \&Senevirate, R. (2011). Factors contributing to medication noncompliance of newly diagnosed smear positive pulmonary TB patients, Asia Pacific Journal Public health, 2 (23): 315-323.

[16] Kamolratanakul, A. (2009). Patient adherence to TB treatment in low income societies, Unpublished Masters dissertation, Harare: University of Zimbabwe.

[17] Kaona, F. A, Tuba, M, Siziya, S. \& Sikaona, L. (2011). An assessment of factors contributing to treatment adherence and knowledge of TB transmission among patients on TB treatment. BMC public health, 29 (4): 68.

[18] Laserso RF and Wells, CD, (2007). Reaching the target for TB control the impact of HIV World Health Organization bulleting 85 (5) 1. 377-381. 